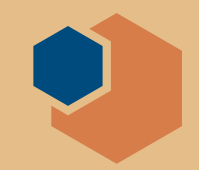

\title{
Latest roadmap of EU's European Strategy Forum continues to fund materials research
}

$\mathrm{O}$ ne of the benefits of doing research inside the EU is the ability to collaborate across borders to maximize the use of scientific resources. In 2002, the EU Council established the European Strategy Forum on Research Infrastructures (ESFRI) to improve how this happens. Research infrastructure includes the facilities and services used by scientists, ranging from research vessels, telescopes, and synchrotrons to biological archives, libraries, and clean rooms. Inspired by the enormous success of one such infrastructure-the CERN particle collider in SwitzerlandESFRI's aim is to solidify Europe as a leader in science and its management.

With an annual budget in the region of $€ 10$ billion for research infrastructures across Europe, according to 2008 data from European Research Infrastructures Development Watch, the potential is enormous. But the process of getting scientists to work together across different international facilities is also slow and laborious. It took four years for ESFRI to publish a roadmap for the development of the next generation of pan-European research infrastructures. By 2010, it contained 48 different projects across a range of scientific fields, of which $60 \%$ were implemented by the end of 2015 .

In their latest roadmap, published in March 2016, ESFRI has added six new infrastructures to "fill in important gaps in the European science landscape," according to the introduction to the roadmap written by outgoing ESFRI Chair John Womersley, Chief Executive of the Science and Technology Facilities Council, the United Kingdom's funding agency for large-scale science facilities and national laboratories. Womersley was replaced by Giorgio Rossi, a professor of physics at the University of Milan, in July 2016.

Materials research is well represented in parts of the roadmap. "ESFRI has a strong portfolio of research infrastructures of direct relevance to materials science and engineering," said Rossi. He added that "the most advanced sources of radiation for the study of the fundamental properties of materials at the nanoscale" is one research goal that has already been implemented with the support of the ESFRI framework.

Environmental science projects constitute a hefty $16 \%$ of the 
entire ESFRI portfolio. One new project is the European Research Infrastructure for the observation of Aerosol, Clouds, and Trace gases (ACTRIS), headquartered in Helsinki, which aims to understand the impact of such gases and particles on the stratosphere and upper troposphere. Developing methods to detect tiny concentrations of these substances requires materials expertise, according to Markku Kulmala, who directs the Division of Atmospheric Sciences of the Physics Department at the University of Helsinki.

Energy research is also heavily reflected in the new ESFRI roadmap. Part of the framework since 2008 is the European Carbon Dioxide Capture and Storage Laboratory (ECCSEL), a project with the aim of eliminating industrial carbon dioxide levels through carbon capture and storage, headquartered at the Norwegian University of Science and Technology in Trondheim. Its aim is to develop new carbon capture and storage facilities as well as upgrading old ones. ECCSEL has nine partner countries, which house 44 research facilities in total, including one at Tiller in Norway and another in Sotacarbo in Italy.

"Being part of ESFRI is important and has affected the project positively," said Volker Röhling, Project Manager for
ECCSEL. He adds that it has also helped in dealing with government departments in partner countries and with funding, marketing, and knowledge exchange between other ESFRI projects.

EU-SOLARIS, a research infrastructure for concentrated solar power, has been in the framework since 2010, headquartered at the Advanced Technology Centre for Renewable Energies in Seville, Spain. Operation is expected to start in 2020.

Another introduced in 2010 is the Multi-purpose Hybrid Research Reactor for High-tech Applications (MYRRHA), headquartered at SCK-CEN, the Belgian Nuclear Research Center in Mol, with partners in Scandinavia, France, and Germany, among others. The MYRRHA design innovatively brings together a nuclear reactor and a particle accelerator. The reactor itself has too little fissile material to maintain the chain reaction needed to produce power, so extra neutrons are provided by the particle accelerator. If successful, it could be used to transmute long-lived radioactive waste from nuclear power plants into shorterlived waste, which could reduce the burden on nuclear-waste disposal.

"Our materials research teams are conducting a support research program addressing liquid metal embrittlement, liquid metal corrosion, irradiation embrittlement of classical austenitic nuclear steels but also some ferritic-martensitic steels," said Hamid Aït Abderrahim, Director of the MYRRHA project.

He said that being part of ESFRI has helped the project draw greater financial support and access to international research networks. "The exposure and recognition of being an ESFRI project strongly increases the visibility of the project on a European and global scale."

The hope is to have each ESFRI project implemented, or to have started construction of large capital-intensive installations, within 10 years.

One unanticipated stumbling block since the framework was announced in March is the United Kingdom's decision to leave the EU. There is no doubt that this will have repercussions for some ESFRI projects. Röhling admits that this will affect his team in the long term because the UK is one of their partners. Kulmala similarly hopes that the "impact is minor."

ESFRI President Giorgio Rossi, meanwhile, is optimistic. "International scientific collaboration is more resilient than other activities when political changes occur," he said.

Angela Saini
US-India partnership announces USD\$30 million expansion to advance clean energy research www.energy.gov

$\mathrm{B}_{\mathrm{s}}^{\mathrm{u}}$ uilding on US international partnerships to accelerate electric grid modernization, research, and deployment, the US Department of Energy (DOE) Office of Electricity Delivery and Energy Reliability has announced a new Funding Opportunity Announcement for joint research on smart grid and energy storage under the US-India Partnership to Advance Clean Energy Research (PACE-R).

The DOE and the Indian Ministry of Science and Technology (MST) are each committing \$1.5 million per year for five years to the expanded research effort, subject to congressional appropriations. The US and Indian private sectors will match the respective government commitments, resulting in a combined $\$ 30$ million public-private research investment over the next five years.

"Smart grid and storage technology will transform how we produce and consume electricity, which has the potential to decrease carbon pollution by scaling up renewable energy deployment," said US Secretary of Energy Ernest Moniz. "Working collaboratively with India will accelerate solutions to drive down technology costs and improve grid resilience and reliability in both countries."

The United States and India launched PACE in 2009 to support research and deployment of clean energy technologies. In 2012, DOE and MST committed to jointly funding research - in a program named PACE-R — with a combined $\$ 50$ million in government funding over five years to launch three initial research consortia, focusing on solar energy, energy efficiency in buildings, and nextgeneration biofuels.

The current expansion provides resources for a fourth consortium under PACE-R that will focus on smart grid and energy storage for grid applications. The new consortium will enable counterparts in the United States and India to leverage the technological research capabilities of both countries. The new consortium will be officially established when an award selection is made-anticipated in 2017. 